Tropical Journal of Pharmaceutical Research April 2016; 15 (4): 687-693

ISSN: $1596-5996$ (print); 1596-9827 (electronic)

(C) Pharmacotherapy Group, Faculty of Pharmacy, University of Benin, Benin City, 300001 Nigeria.

All rights reserved.

Available online at http://www.tjpr.org

Original Research Article

http://dx.doi.org/10.4314/tjpr.v15i4.3

\title{
Humoral and cellular immune responses to modified hepatitis $B$ plasmid DNA vaccine in mice
}

\author{
Mounir M Salem-Bekhit ${ }^{1,2 *}$, Mohamed Osman Gad El Rab ${ }^{3}$, Mahmoud M \\ Tawfick', Mohammad Raish", Mohamed Dahmani ${ }^{4}{ }^{4}$ athallah ${ }^{5}$ and Mohsen \\ Bayomi $^{3}$ \\ ${ }^{1}$ Microbiology and Immunology Department, Faculty of Pharmacy, Al-Azhar University, Cairo, Egypt, ${ }^{2}$ Kayyali Chair for \\ Pharmaceutical Industries, College of Pharmacy, PO Box 2457, ${ }^{3}$ Department of Pathology, Immunology Division, College of \\ Medicine, King Khalid University Hospital, ${ }^{4}$ Department of Pharmaceutics, College of Pharmacy, PO Box 2457, King Saud \\ University, Riyadh 11451, Saudi Arabia, ${ }^{5}$ Biotechnology Program, College of Graduate Studies, King Fahd Chair for Health \\ Biotechnology, Arabian Gulf University, Manama, Bahrain
}

*For correspondence: Email: mounirmsalem@yahoo.com, mbekhet@ksu.edu.sa; Tel: +966 501783166

Received: 7 November 2015

Revised accepted: 10 March 2016

\begin{abstract}
Purpose: To evaluate the immunogenicity and types of immune response of a quality-controlled modified recombinant hepatitis B surface antigen (HBsAg) plasmid encoding HBsAg in mice.

Methods: The characterized plasmid DNA was used in the immunization of Balb/c mice. Three groups of mice were intramuscularly injected with three different concentrations (50,25 and $10 \mu \mathrm{g} / 100 \mu \mathrm{L}$ ) of the modified plasmid. Humoral immune response was monitored by enzyme-linked immunosorbent assay (ELISA), while cellular immune response was investigated by analysis of spleen cytokine profile (TNFa, IFN $Y$ and IL2) as well as CD69 expression level in CD4 and CD8 positive cells.

Results: In general, the activated CD4 cells showing intracellular cytokines were higher than CD8 positive population of cells $(p<0.05)$. These findings indicate that the vaccine induced both a humoral and cellular immunity. Cytokine profile also showed high levels of TNFa, IFN $y$ and IL2 and CD69 expression in the group of animals immunized at a dose of $10 \mu \mathrm{g}$ when compared to control group ( $p<$ 0.05).

Conclusion: $A 10 \mu g$ dose intramuscular injection of the modified DNA-based vaccine encoding HBsAg in mice induces both high humoral and cellular immune responses.
\end{abstract}

Keywords: Hepatitis B virus, Plasmid DNA, Vaccine, Spleen cytokines, Humoral and cellular immune responses

Tropical Journal of Pharmaceutical Research is indexed by Science Citation Index (SciSearch), Scopus, International Pharmaceutical Abstract, Chemical Abstracts, Embase, Index Copernicus, EBSCO, African Index Medicus, JournalSeek, Journal Citation Reports/Science Edition, Directory of Open Access Journals (DOAJ), African Journal Online, Bioline International, Open-J-Gate and Pharmacy Abstracts

\section{INTRODUCTION}

Hepatitis $B(H B)$ is a potentially life-threatening liver infection caused by Hepatitis B virus (HBV) [1]. It is an important worldwide health concern, more than 240 million are chronic carriers according to World Health Organization (WHO) [2]. DNA-based immunization is an efficient technique to induce humoral (antibody) and cellular ( $T$ cell) immune responses.

The use of DNA-based vaccines has recently attracted much attention and shown promising outcomes by stimulating the immune system [3]. The protection against HBV infection depends on strong antibody response. Th1-type and cytotoxic $T$ cells (CTL) responses to HBV and the 
associated antiviral cytokines (TNF- $\alpha$, IFN- $\alpha$, and IL-2) might play a major role in virus resolution during natural infection.

Antigen presentation includes primarily foreign protein degradation in the host cells through association of proteolytic fragments with two different types of major histocompatibility complex (MHC) proteins (class I and class II $\mathrm{MHC}$ ) which present degraded protein fragments to T-cells. Thus, the ability of DNA vaccine to elicit both humoral and cell mediated immune responses is a great advantage of using DNA vaccine [4].

The purpose of the present investigation was to assess the immunogenicity of previously reported DNA-HBsAg - based vaccine comprising modified gWiz-HBsAg plasmid, characterized and quality-controlled by SalemBekhit et al [5], and type of immune responses produced in mice.

\section{EXPERIMENTAL}

\section{Vector and expression plasmids}

The $\mathrm{gWiz}^{\mathrm{TM}}$ expression vector, used as control in the quality control experiments, and the hepatitis B DNA vaccine recombinant plasmid gWiz ${ }^{\text {TMHBsAg }}$ (gWiz ${ }^{\text {TM }}$ plasmid harbours HBsAg encoding nucleotide sequence) were purchased from Aldevron, USA. The full integrity and quality of the nucleotide sequence of gWizHBsAg plasmid was characterized and previously controlled previously [5]. The quality controlled recombinant plasmid gWizHBsAg was used in mice immunization experiments performed in this study.

\section{Modified gWiz ${ }^{\text {TMHBsAg plasmid mice }}$ immunization}

The recombinant modified gWizHBsAg plasmid (6.435 kbp long and had a pUC origin of replication. Aldevron, USA). previously reported by Salem-Bekhit et al [5]. Briefly, The gWi zHBs have sequentially propagated in Escherichia coli DH5 $\alpha$ strain, Genotype: F- endA1 glnV44 thi-1 recA1 relA1 gyrA96 deoR nupG \$80dlacZ $\Delta M 15$ $\Delta$ (lacZYA-argF)U169, hsdR17(rK- $\mathrm{mK}+), \lambda$. The gWiz high-Expression $\mathrm{HBsAg}$ plasmid (gWizHBsAg) $5 \mathrm{mg}$. The prepared plasmid was analyzed, using agarose gel electrophoresis, DNA restriction profiling and DNA sequencing. The gWizHBsAg plasmid was used for immunization of 21 female Balb/c mice aged 6-8 weeks bred in King Saud University (KSU) animal house and kept under specific pathogen free conditions. These mice were divided into three groups (A, B and C), each group comprised seven mice. Mice received intramuscular (IM) injections by insulin syringe (Becton-Dickinson, Franklin Lakes, NJ, USA) in the quadriceps muscles of the hind limbs. The three groups A, B and $C$ received different doses of gWizHBsAg plasmid DNA dissolved in $100 \mu \mathrm{L}$ of normal saline $50 \mu \mathrm{g} / 100 \mu \mathrm{L}, 25 \mu \mathrm{g} / 100 \mu \mathrm{L}$ and 10 $\mu \mathrm{g} / 100 \mu \mathrm{L}$, respectively. Mice were boosted with a dose of $4 \mu \mathrm{g}$ after 2 weeks from the initial immunization. Ethical approval for the animal study was obtained from the Ethics Committee of the College of Pharmacy, KSU, Riyadh, Saudi Arabia.

\section{Mice bleeding and detection of specific antibodies against $\mathrm{HBsAg}$}

Serial bleedings were performed at different time points starting with pre-immunization bleeding at the beginning and then at weekly interval up to 6 weeks after the first immunization. The blood samples were analyzed for the presence of HBsAg-specific IgM antibodies from week 0, 1, 2, 3 and 4 and starting from weeks $3,4,5$ and 6 for the detection of HBsAg-specific IgG antibodies. Microtitre plates of ELISA kits (Alpha Diagnostic International, U.S.A) coated with HBsAg protein were used for the detection anti-HBsAg antibodies. In brief, $100 \mu \mathrm{L}$ of serum diluted in 1:200 was added to each well then incubated for one hour at $25{ }^{\circ} \mathrm{C}$. After the samples were washed with PBS, bound proteins were detected with HRP-conjugated goat anti-mouse IgM or anti-mouse IgG. Color was generated by adding reaction stop solution and the absorbance was measured at $450 \mathrm{~nm}$ by ELISA reader. ELISAs were performed and HBsAg specific IgM and IgG antibodies were calculated according to the manufacturer's instructions.

\section{Isolation and culturing of splenocytes isolated from immunized mice}

To determine the cellular reaction of the modified gWizHBsAg plasmid immunization, the spleen, following six-week immunization course, were isolated from the three groups of mice, $A, B$, and $\mathrm{C}$, and splenocytes were cultured as follows. Briefly, immediately after mouse sacrifice, spleen was put in a clean Petri-dish with a suitable tissue culture medium, disrupted mechanically using a $5 \mathrm{ml}$ syringe head after cutting into small pieces and passed through a nylon cell strainer (Becton Dickinson, New Jersey, USA). Contaminating red blood cells were lysed using $0.83 \%$ ammonium chloride and incubated at 37 ${ }^{\circ} \mathrm{C}$ for $5 \mathrm{~min}$. In ice-cold RPMI 1640 tissue culture medium supplemented with $10 \mathrm{mM}$ fetal bovine 
serum, $10 \mathrm{mM}$ HEPES, $2 \mathrm{mM}$ glutamine, 100 $\mathrm{U} / \mathrm{mL}$ streptomycin and $100 \mathrm{U} / \mathrm{mL}$ penicillin the cells were suspended.

\section{Finding of splenocytes surface markers and intracellular cytokines}

HBsAg-specific CTL assay was performed using panels of monoclonal antibodies used for the detection of surface markers and intracellular cytokines of immunized splenocytes. Splenocyte concentration of $2 \times 10^{6} / \mathrm{mL}$ was stained in 4 test tubes:- 1- CD4 FITC, CD69 PE and Tumor Necrosis Factor (TNF) precp, 2- CD4 FITC, IL2 PE and INF-y precp., 3- CD8 FITC, CD69 PE and TNF precp., 4- CD8 FITC, Interleukin-2 (IL2) PE and INF-y precp. Surface marker monoclonal antibodies were added first to stain the cells for 20 min in the dark, cells were then washed with cold $5 \%$ BSA/PBS and the pellet was resuspended in complete RPMI. The cells were fixed and permeablized with $100 \mu \mathrm{L}$ of $\mathrm{BD}$ Cytofix/Cytoperm buffer and incubated for $20 \mathrm{~min}$ at room temperature. Thereafter, $20 \mu \mathrm{L}$ of cytokine monoclonal antibodies were added, incubated for $15 \mathrm{~min}$, washed 3 times and suspended in BD Pharmingen stain buffer. Data acquisition and analysis were obtained by flow cytometer.

\section{Statistical analysis}

The data were processed by SPSS 11.5 software. For each set of data, mean and standard deviation (SD) were calculated. IgM and IgG values were plotted against time and histograms were built to compare the values obtained for cytokines. Statistical significance of differences was defined as $p<0.05$.

\section{RESULTS}

\section{DNA plasmid encoding HBsAg induces humoral immune response in BALB/c mice}

The humoral immunity was evaluated by detecting specific HBsAg IgG and IgM induced by modified DNA HBsAg plasmids in BALB/C immunized mice. ELISAs results showed that $\mathrm{HBsAg}$ specific $\lg \mathrm{G}$ and $\lg \mathrm{M}$ antibodies were detectable in the sera of the immunized mice groups $A, B$ and $C$. The baseline reading of the pr-immunization bleed sera showed an $\mathrm{OD}_{450 \mathrm{~nm}}$ of 0.15 . The group A mice, which received a total of $20 \mathrm{mg}$ of modified plasmid DNA-HBsAg over the six-week immunization course, demonstrated IgM antibodies as early as one week after the first immunization showing a detectable signal at an $\mathrm{OD}_{450 \mathrm{~nm}}$ of 2.8. However, in the following $2 \mathrm{nd}$ and 3rd weeks showed a gradual drop to an $\mathrm{OD}_{450 \mathrm{~nm}}$ of 1.5. However, at the 4th week, the IgM level showed a rise up to $O_{450 \mathrm{~nm}}$ of 2.0. IgG antibodies were detectable starting from the 3rd week after the first immunization giving an $\mathrm{OD}_{450 \mathrm{~nm}}$ of 0.18 . Thereafter, IgG level started to decrease gradually in the 5th and 6th weeks to $0.1 \mathrm{OD}_{450 \mathrm{~nm}}$. The collective results for IgM and IgG levels for group A mice are shown in Figure $1 \mathrm{~A}$.

In immunized mice group $B$, which received a total of $10 \mathrm{mg}$ of modified DNA-HBsAg plasmid by the I.M. route, IgM antibodies were detectable at a level of $0.35 \mathrm{OD}_{450 \mathrm{~nm}}$ in the sera of the first bleed sample after one week of immunization. In the following bleedings at the 2nd, 3rd and 4th week, the IgM antibodies levels were almost maintained. On the other hand, IgG antibodies were detectable at a level of $1.0 \mathrm{OD}_{450 \mathrm{~nm}}$ in the 3rd week. The level of IgG antibodies was then increased to $0.15 \mathrm{OD}_{450 \mathrm{~nm}}$ in the 4th week and to $2.5 \mathrm{OD}_{450 \mathrm{~nm}}$ in the 5th week. Afterwards, the level of $\operatorname{lgG}$ antibodies started to decrease gradually to a level of $0.1 \mathrm{OD}_{450 \mathrm{~nm}}$ at the 6th week. The collective results for IgM and IgG levels for this group are shown in Figure 1B.

In group $C$ mice which received a total of $4 \mathrm{mg}$ of modified plasmid DNA-HBsAg over the immunization course, IgM antibodies level were detectable after one week from the first immunization of $0.35 \mathrm{OD}_{450 \mathrm{~nm}}$. The level dropped gradually to 0.3 and $0.29 \mathrm{OD}_{450 \mathrm{~nm}}$ in the $2 \mathrm{nd}$ and 3rd week bleeds, respectively, and then increased to $0.3 \mathrm{OD}_{450 \mathrm{~nm}}$ at the 4th week. The IgG antibodies level were detectable in a level of $0.15 \mathrm{OD}_{450 \mathrm{~nm}}$ at the $3 \mathrm{rd}$ week, then the level increased to $0.22 \mathrm{OD}_{450 \mathrm{~nm}}$ in the 4th week and dropped to $0.15 \mathrm{OD}_{450 \mathrm{~nm}}$ at 5 th week. At the 6th, week the IgG antibodies level again increased to $0.2 \mathrm{OD}_{450 \mathrm{~nm}}$. The collective $\operatorname{lgM}$ and IgG antibodies levels for this group are shown in Figure 1C.

\section{Activation of cellular immunity in BALB/c mice}

The cellular immunity in DNA-HBsAg plasmid immunized BALB/c mice was assessed by detecting the CD4+ and CD8+ cells. Activation of CD4+ and CD8+ cells was examined in the three groups of immunized mice by measuring the number of cells showing intracellular cytokine release, TNF, INF- $y$ and IL-2. The activation marker CD69 was also measured. 
A

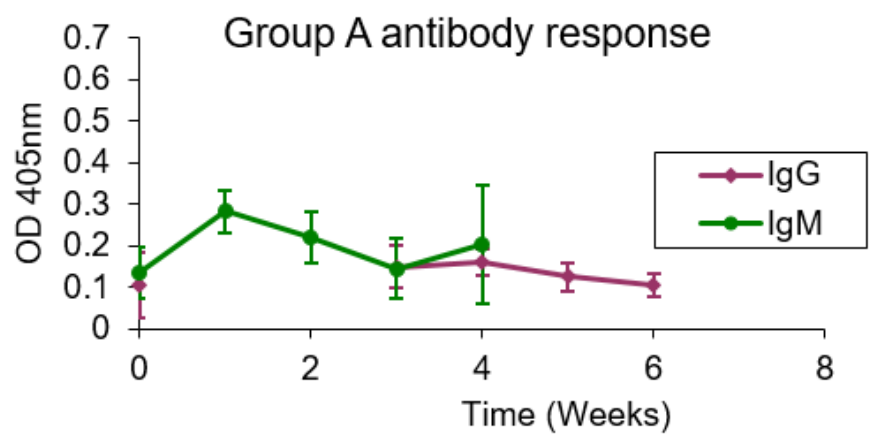

B
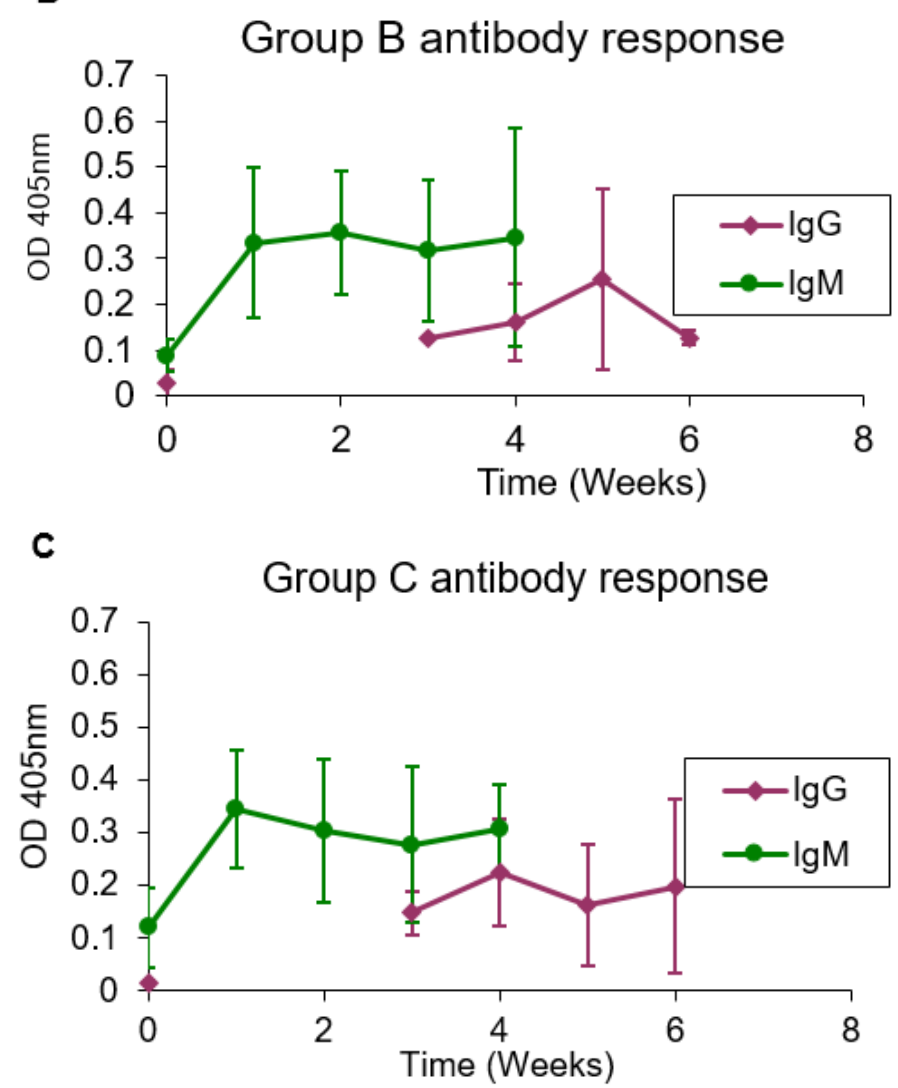

Figure 1: HBsAg-specific IgM and IgG levels in modified plasmid DNA-HBsAg immunized mice groups following I.M injection over the six-week immunization course: A, group A which treated with $40 \mathrm{mg}$ of modified plasmid; B, group B which treated with $20 \mathrm{mg}$ of modified plasmid; C, group $\mathrm{C}$ which treated with $4 \mathrm{mg}$ of modified plasmid

Activation of CD4+ cells for the three groups of immunized mice is shown in Figure $2 \mathrm{~A}$. It was found that $30 \%$ of CD4+ cells in group C mice were actually producing TNF as compared to 21 and $5 \%$ in groups $A$ and $B$, respectively. For INF-Y as shown in Figure $2 A$, $28 \%$ of CD4+ cells from mice group $\mathrm{C}$ showed detectable intracellular INF- $\mathrm{y}$. While, in groups $B$ and $A$, mice 20 and $8 \%$ of the CD4+ cells were actively producing INF- $\mathrm{y}$, respectively. CD4+ cells from group B mice showed $18 \%$ of activated cells secreting IL-2, while, it is $10 \%$ in group $\mathrm{C}$ and only $2 \%$ in group $A$. The activation marker, CD69, was detected in equal number in both group B and group C where $14 \%$ of the CD4+ cells were positive, however, in group $A$, only 4 $\%$ of the CD4+ cells were positive for the marker.

In the case of CD8+ cells (Figure 2B), intracellular TNF was detected in $23 \%$ of cells in group C, mice while $18 \%$ in group $B$ and $2.5 \%$ in group A were secreting TNF. For INF-y, CD8+ cells from group $\mathrm{C}$ mice showed also the highest number of activated cells secreting INF-y (24\%). In group $B$, mice $18 \%$ of cells were active and in group A only $4 \%$ of cells showed INF-y. IL-2 was detected in $5 \%$ of the cells from mice group $\mathrm{C}$; mice while in groups $A$ and $B$, only $2 \%$ were 
positive for IL-2. CD8+ cells from group C mice showed $15 \%$ of cells expressing CD69, while the marker was only detected in 2 and $5 \%$ of CD8+ cells in groups $A$ and $B$, respectively.

\section{DISCUSSION}

The best way to prevent hepatitis $B$ is by receiving hepatitis $B$ vaccine. It is important to accelerate the vaccination schedule against hepatitis $B$ because it might increase patient compliance in addition to offering earlier protection for the high-risk group or environment. HBV infection is considered to be one of the dominant problem in most countries worldwide, specifically those in the Middle East, Asia, and Africa [6-8]. Hepatitis B infection is the major cause of diseases of liver such as cirrhosis and hepatic carcinoma. Despite the occurrence of HBV infection that has declined fallowing mass $\mathrm{HB}$ vaccination programs, the average incidence of chronic HBV infection internationally is estimated at $6.6 \%$ [7]. The rate of $\mathrm{HbsAg}$ positivity among the vaccinated group was $0.8 \%$ in comparison with $2.2 \%$ among the nonvaccinated group. The study concluded that the efficacy of $\mathrm{HB}$ vaccine in inhibiting the carriage of $\mathrm{HbsAg}, 5$ years after full course vaccination, was assessed to be around $67 \%$ in Egypt [9].
One month [10] after the third dose, the seroprotection was $(96.5 \%)$ with mean geometric anti-HBs titers of $2560.0 \mathrm{mIU} / \mathrm{mL}$ was indicated through the experimental data that were obtained during the trial course. In addition, twenty subjects as a whole in the age group of $40-49$ years $(11 / 307 ; 3.5 \%)$ had resulted an antibody titer of $8.60 \mathrm{mIU} / \mathrm{mL}$ and presented a low response to the vaccine. While all tested subjects attained $100 \%$ seroconversion [11], risk factors associated with non-response to hepatitis $B$ vaccine included age, gender, history of smoking and route of administration of vaccine [12].

Viral vectors and recombinant DNA have been used for years in human clinical trials and in laboratory animals as vectors for $\mathrm{Ag}(\mathrm{s})$ of interest to make strong effector and memory CD4_ and CD8_ T cell responses in both the treatment and inhibition of diseases [13-15].

Results from this study show that both humoral and cellular immune responses were induced in mice by the intramuscular injection of a modified plasmid DNA-HBs Antigen. In all three groups of mice, $A, B$ and $C$ which received 20,10 and $4 \mu \mathrm{g}$ of vaccine, respectively, the antibodies of lgM class were detectable at a comparatively high concentration in the 3rd week.

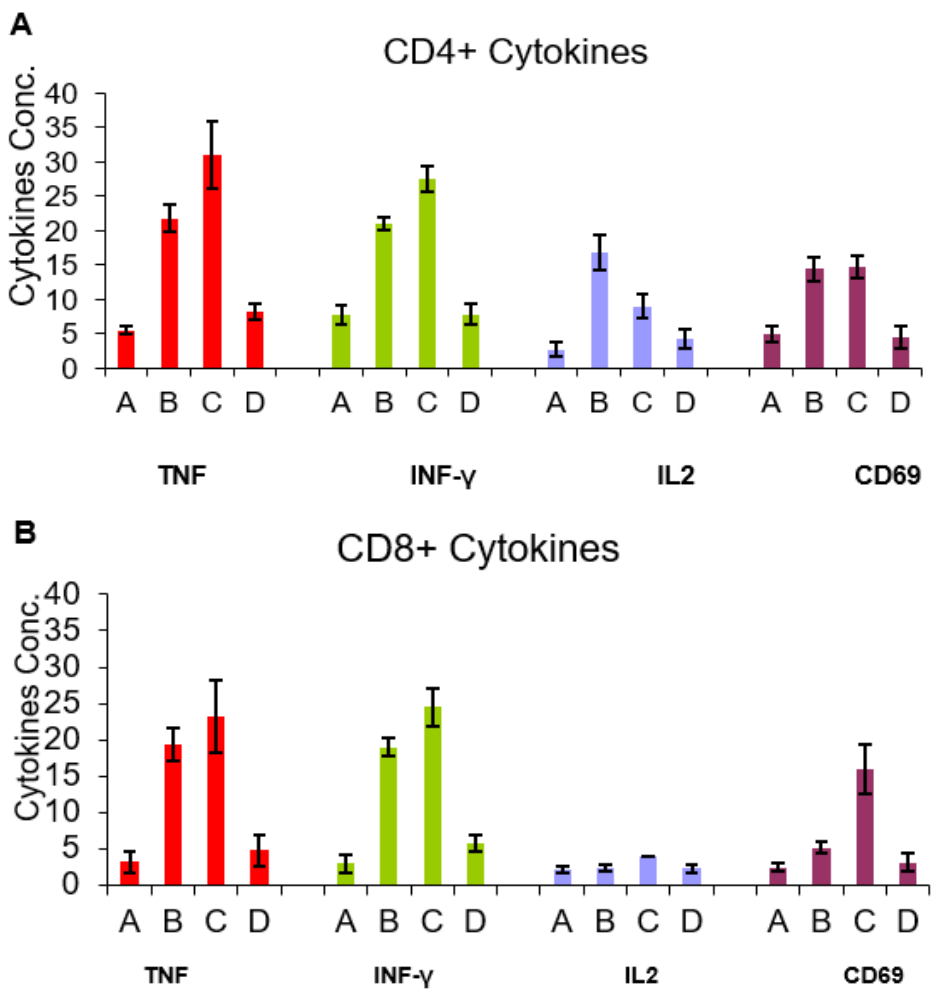

Figure 2: Assessment of cellular activation in modified plasmid DNA-HBsAg immunized mice groups following I.M injection: A, data for CD4+ cells; $\mathbf{B}$, data for CD8+ positive cells, data for four the three immunized groups $A$, $B, C$ and fourth negative control group $D$ 
This finding confirms the induction of a primary response to the injected vaccine (16). It has been documented that specific cellular immunity against HBV is a key factor in the control of HBV infection $[17,18]$. IgM level decreased gradually in all three groups over the following two weeks and then showed a rise at the 4th week. As a consequence of the booster doses given to the animals, IgG type of antibodies appeared the 3rd week in all the groups. This indicates a normal secondary response to the injected vaccine. The IgG level started to decrease gradually thereafter. It is also noted that $\operatorname{lgM}$ showed higher levels as compared to IgG. This could be due to the concentration of the booster doses administered.

Compared to groups $A$ and $B$, group $C$ showed the best results. This may be taken to indicate that the best immunizing dose in this experiment lies in the range of $4 \mu \mathrm{g}$. In this group, higher levels of IgM were detected and showed a sustained level up to the 4th week. IgG antibodies became detectable at the 3rd week and also maintained an almost constant level up to the 6th week. Cellular responses to the modified DNA-HBs antigen vaccine were assessed in splenocytes isolated from the immunized mice by measuring intracellular cytokines (IFN- $y$, TNF, IL-2 and the activation marker CD69) in CD4+ and CD8+ cells. In general, the percent of activated CD4+ cells showing intracellular cytokines was higher than the CD8+ population of cells. This is expected since CD4+ helper cells are usually higher than CD8+ cytotoxic cells.

Another observation worthy of note, the cytokines detected IFN- $y$ and TNF indicates a Th2 type of response. Viral antigens are known to drive T-helper cells into the Th2 type. It is also interesting to note that group $\mathrm{C}$ mice again showed the best cellular response. As appeared in the results, IL-2 was the least cytokine detected and the number of CD8+ cells secreting this cytokine was very low. In summary, results from this experimental study in BALB/c mice demonstrated that I.M. injection of a DNA-HBs antigen in a dose of $10 \mu \mathrm{g}$ induced both humoral and cellular immune responses. Further studies may be needed to adjust the dose and timing of the booster doses to give a sustained immune response. Engaging therapeutic hepatitis $B$ vaccines is a new approach against hepatitis $B$ infection $[19,20]$. The cytokines (IFN-y, TNFa, IL2 and CD69) in CD4+ and CD8+ cells perform a vital role in various stages of viral infection [2124]. However, experiments which are carried out in vivo and in vitro showed that secretion of Th1 cytokines (IFN- $y$ and TNF- $\alpha$ ) play an important part in HBV elimination from hepatocytes [25,26]. Hepatitis $B$ vaccine administered through gene therapy showed enhanced cytokines level in patients with Hepatitis B. The direct administration of cytokines seems to be a more efficient method for viral infection removal [20].

\section{CONCLUSION}

The findings of this study demonstrate that I.M. injection of a DNA-HBs antigen at a dose of 10 $\mu \mathrm{g}$ induces both humoral and cellular immune responses in BALB/c mice. Further studies are required to adjust the dose and timing of the booster doses to give sustained immune response.

\section{ACKNOWLEDGEMENT}

The authors extend their appreciation to Deanship of Scientific Research at King Saud University for funding this work through Research Group Project no. RGP-202.

\section{REFERENCES}

1. Komatsu H. Hepatitis $B$ virus: where do we stand and what is the next step for eradication? World J Gastroenterol 2014; 20: 8998-9016.

2. Organization WH. Hepatitis B. Accessed by September 4, 2013. Media Centre. 2013.

3. Wolff $A$, Malone W, Williams $P$, Chong W, Acsadi G, Jani A. Direct gene transfer into mouse muscle in vivo. Sci 1990; 247(4949 Pt 1): 1465-1468.

4. Geiben-Lynn R, Greenland R, Frimpong-Boateng K, van Rooijen N, Hovav H, Letvin L. CD4+ $T$ lymphocytes mediate in vivo clearance of plasmid DNA vaccine antigen expression and potentiate CD8+ T-cell immune responses. Blood 2008; 112: 4585-4590.

5. Salem-Bekhit $M$, Jamous $Y$, Al-Anazi $F$, Bayomi $M$, Alsarrah I, Fathallah MD. Quality control of optimized hepatitis B plasmid DNA vaccine. Afr J Biotech 2012; 11: 1231-1239.

6. Andre F. Hepatitis $B$ epidemiology in Asia, the Middle East and Africa. Vaccine 2000; 18: S20-22.

7. Chen J, Wang $Y, Y u$ W. Epidemiology of hepatitis $B$ virus infection in the Asia-Pacific region. $J$ Gastroenterol Hepatol 2000; 15: 3-6.

8. Ott J, Stevens A, Wiersma T. The risk of perinatal hepatitis $B$ virus transmission: hepatitis $B$ antigen (HBeAg) prevalence estimates for all world regions. BMC Infect Dis 2012; 12: 131-138.

9. Reda A, Arafa A, Youssry A, Wandan H, Ab de Ati M, Daebees $H$. Epidemiologic evaluation of the immunity against hepatitis $B$ in Alexandria, Egypt. Eur J Epidemiol 2003; 18: 1007-1011. 
10. Elavia J, Marfatia P, Banker D. Immunization of hospital personnel with low-dose intradermal hepatitis $B$ vaccine. Vaccine 1994; 12: 87-90.

11. Hussain Z, Ali S, Husain A, Raish M, Sharma R, Kar P. Evaluation of immunogenicity and reactogenicity of recombinant DNA hepatitis $B$ vaccine produced in India. World J Gastroenterol 2005; 11: 7165-7168.

12. Das K, Gupta K, Kumar V, Kar P. Immunogenicity and reactogenicity of a recombinant hepatitis $B$ vaccine in subjects over age of forty years and response of a booster dose among nonresponders. World $J$ Gastroenterol 2003; 9: 1132-1134.

13. Moore C, Hill V. Progress in DNA-based heterologous prime-boost immunization strategies for malaria. Immunol Rev 2004; 199: 126-143.

14. McConkey J, Reece H, Moorthy S, Webster D, Dunachie $S$, Butcher G. Enhanced T-cell immunogenicity of plasmid DNA vaccines boosted by recombinant modified vaccinia virus Ankara in humans. Nat Med 2003; 9: 729735.

15. Anderson J, Hannan M, Gilbert C, Laidlaw M, Sheu G, Korten S. Enhanced CD8+ $T$ cell immune responses and protection elicited against Plasmodium berghei malaria by prime boost immunization regimens using a novel attenuated fowlpox virus. J Immunol 2004; 172 . 3094-3100.

16. Davis L, Mancini M, Michel L, Whalen G. DNA-mediated immunization to hepatitis $B$ surface antigen: longevity of primary response and effect of boost. Vaccine 1996; 14 : 910-915.

17. Rehermann B, Lau D, Hoofnagle JH, Chisari FV. Cytotoxic $T$ lymphocyte responsiveness after resolution of chronic hepatitis B virus infection. J Clin Invest 1996; 97: 1655-1665.

18. Bertoletti A, Gehring J. The immune response during hepatitis $B$ virus infection. J Gen Virol 2006; 87: 14391449.

19. Kosinska D, Zhang E, Lu M, Roggendorf M. Therapeutic vaccination in chronic hepatitis $B$ : preclinical studies in the woodchuck. Hepat Res Treat 2010; 12: 1-17.

20. Roggendorf $M$, Schulte I, XU Y, Lu M. Therapeutic vaccination in chronic hepatitis $B$ : preclinical studies in the woodchuck model. J Viral Hepat 2007; 14: 51-57.

21. Mondelli U, Varchetta S, Oliviero B. Natural killer cells in viral hepatitis: facts and controversies. Eur J Clin Invest 2010; 40: 851-863.

22. Bertoletti A, Maini MK. Protection or damage: a dual role for the virus-specific cytotoxic $T$ lymphocyte response in hepatitis B and C infection. Curr Opin Microbiol 2000; 3: 387-392.

23. Isogawa M, Furuichi $Y$, Chisari FV. Oscillating CD8(+) $T$ cell effector functions after antigen recognition in the liver. Immunity 2005; 23: 53-63.

24. Matter S, Hilmenyuk T, Claus $C$, Marone R, Schurch $C$, Tinguely M. Destruction of lymphoid organ architecture and hepatitis caused by CD4+ T cells. PLoS One. 2011; 6: 24-27.

25. Wieland F, Guidotti G, Chisari V. Intrahepatic induction of alpha/beta interferon eliminates viral RNA-containing capsids in hepatitis $B$ virus transgenic mice. J Virol 2000; 74: 4165-4173.

26. Suri $D$, Schilling $R$, Lopes $R$, Mullerova I, Colucci $G$, Williams $R$. Non-cytolytic inhibition of hepatitis $B$ virus replication in human hepatocytes. J Hepatol 2001; 35: 790-797. 